\title{
Study on the Teaching Reform in Probability Theory and Mathematical Statistics
}

\author{
Chunguang Zhao \\ Department of Mathematics \\ Handan College \\ Handan, China \\ Zhaochunguang888@126.com
}

\author{
Haijun Chen \\ Department of Mathematics \\ Handan College \\ Handan, China
}

\author{
Yulong Zhu \\ Department of Mathematics \\ Handan College, Handan, China
}

\begin{abstract}
According to the current situation of the local colleges and the theory of probability and mathematical statistics in teaching practice, how to design teaching content and teaching methods, etc, the paper puts forward the suggestions and measures in teaching reform for this course.
\end{abstract}

Keywords- teaching reform; teaching method; probability theory and mathematical statistics

\section{INTRODUCTION}

At present, "Probability theory and mathematical statistics" is a required course in higher learning institutions for mathematics majors and one of the difficult courses[1]. It is difficult to master this course for students because of abstract conception, so students lack interesting in learning it. For improving the effectiveness of classroom teaching, teaching reform is imperative. In recent years, many colleges have conducted a series of exploration from the teaching aim, content, method, means, and have got some experience in Probability and statistics curriculum.

For a long time, teachers mostly cram students by single instruction in the teaching process, the interrelated concepts and conclusions were separated to explain, so that students can not understand the theory, the complex formula is not easy to remember and use for students, the application of statistical knowledge is low. In the process of teaching, teachers only focus on the inculcation of knowledge, but do not pay attention to the cultivation of innovation ability; teachers who pay attention to the formula theory do not pay attention to the practical problems[2]. Probability theory and mathematical statistics teaching reform has become an urgent problem to be solved.

In this paper, it further defines the direction of reform the teaching of probability and statistics, In order to improve the effectiveness of teaching probability, develop the students' ability to use the probability statistics method to analyze problems and improve the students' practice ability and innovation ability. Combining the teaching practice and experience, it provides some suggestions on how to design the teaching content and teaching method in Probability and statistics.

\section{DEFINITION、THEORY EXPLANATION}

Many definitions of probability theory and mathematical statistics have the intuitive background, so we introduce definitions according to the background. Many theories of probability theory and mathematical statistics from the practice, so teachers should teach according to the actual application in the explanation of related theory on statistical problems in all aspects of life, that can arouse the students' interest about the development history of the subject.

\section{Definition explanation}

Example: The mathematical expectation of the random variable describes the mean value, correlation coefficient describes the degree of two random variables linear correlation. This will have a multiplier effect, if educators properly discuss its significance before introduced the definition[5].

\section{Theory explanation}

Example: Hypothesis testing is a very important part in mathematical statistics, its theoretical basis originates from that the small probability event in one test is not possible identity, its reasoning is based on the logic of reduction to absurdity in statistical sense. Some students often blindly memorizing for don't know their way of thinking, that may be wrong once encountering problems, so teachers should grasp the essence of the key from reality, the original hypothesis selection and inspection level to determine the relationship between the types of errors, and second types of errors of the rejection region of a detailed explanation of the method, and then the abstract general steps. Teachers should give the students reading after class for select some relevant statistics, so that can expand their knowledge and improve their ability.

The thought, origin and development of probability theory and mathematical statistics is fascinating,. In the teaching process, teachers should research questions in all aspects of life, penetration of mathematical history and development of probability theory, it have made outstanding contributions such 
as Bias, Bernoulli, Gauss, Fischer et al., contacting the textbook to introduce their achievements, it enabling students to understand the background of the development of science of probability and statistics, so that students in learning knowledge and at the same time, to understand the history of probability and statistics, so that can stimulate students' interest. Such as: when explaining the statistics in the t- distribution, Fdistribution, I introduced to students how three commonly used distribution is set up and the relevant historical data and their creator. Such as t- distribution was proposed by Gossett in 1899, Gossett appointed winemaker in a brewery, in the experiment and data analysis, small sample experiment was carried out in this work results that he suspected that does not belong to other distribution normal distribution curve, through research, finally get the density curve of new, and in 1908 to student pseudonym published the results, so called the distribution for the student's distribution or $\mathrm{t}$ - distribution. Through the introduction, we can make the students understand the subject of history, and lead the students not only to learn knowledge from books, but also to be good at thinking, be courageous to discover and solve problems, and gradually cultivate students' innovation consciousness. These attempts and achieved in the teaching process have had good results.

\section{THE CASE TEACHING METHOD}

First, confirm Case teaching is under the guidance of teachers, the case as a teaching material, students study analysis and debate on the case to judge the problem based on the curriculum teaching goal; Through the analysis of the case, enabling students to participate in the discussion, the theoretical knowledge and practical life science combined, the abstract mathematics combined with the lively and interesting case, which can mobilize the initiative and enthusiasm of students, and students' ability to analyze and solve problems.

At the same time of Paying attention to the teaching of the course content in the application background and the way of thinking, teachers should make students hands-on, collect and process data, use the theory of probability and mathematical statistics to solve practical problems. For example: the normal distribution is the probability theory and mathematical statistics, the most commonly used one kind of probability distribution, it is widely applied in solving practical problems. Experience shows that, when the effect of random factors of a variable by a large number of small, independent of each other, this variable is often subject to or approximately obey the normal distribution.

The students 'grades is a random variable before the exam, probably under the influence of the learning of students, teachers' teaching skills, papers such as ease of random factors. Under normal circumstances, results similar to normal distribution. In the study of normal distribution, let the students do a survey to the college students on mathematical analysis ,draw the score histograms, compared with the density function curve of normal distribution, and analyzed the differences between them. If the two has significant differences, then a random factor is not normal. The possible causes may be the students are not diligent enough or the teaching method is improper, or the test is too hard to the students . We can find out the reasons through the analysis, it can be used to guide the teaching management departments to formulate corresponding management regulations, to guide the teaching, better services to students; and, to rate of mobile phone in students learning mathematical statistics section, using the related statistical knowledge, make the assumption that in advance, then collect the relevant data, test the hypothesis. This extremely beneficial to explore the current consumption level of college students, value orientation. And by the law of large numbers, when the frequency of random experiment is large enough, the frequency will be gradually stable in probability event. The problem of teaching for just contact probability and statistics of the students, it is difficult to accept. But if the practical problems in the coin toss a random experiment in teaching, we will get twice the result with half the effort. On the one hand it not only enable the students to grasp the law of large numbers, but also educates the students to seek truth from facts, and find the universal law of the development and change of things from the actual problem. On the another hand this activity not only stimulates the student to study and apply knowledge and enthusiasm, but also cultivates students' ability to understand and apply the course content.

\section{THE EXPERIMENTAL TEACHING METHOD}

In the traditional teaching process, it usually only emphasizes the completeness of theory, but ignore the cultivation of students' ability and practice ability, thinking method does not use the course to solve practical problems. In order to reform, the abuses of traditional teaching, it is necessary to set up the experimental course in the teaching process, learning proper computer technology and statistical analysis software, to enhance students' practical ability[6].

Random experiment, through a certain experiment designed, some observation data of random phenomena were analyzed, the establishment of various probability, statistical models, methods are described and the research on the stochastic phenomena. This method is an important method of probability theory and mathematical statistics research, it can help students to learn and understand the relevant theory.

We created three random experiments in teaching: the first is the operation of experimental physics of describing the random phenomena mainly by means of experiment operation in some physical tools, Such as the Galton experiment board, the experimental process itself is very simple, presented the results of visual image, but which contains the relevant theoretical knowledge that very rich, which can be used to complete the three theory questions of teaching: one is the frequency stability of random events present in repeated trials; two is Bei Nouri test of success times follow two distribution; three is the Dymov-Laplasse central limit theorem. These theories are complex and abstract to students, not easy to understand and remember, so that it is the difficult point of teaching. Using the Galton experiment, brings freshness to the students, stimulates students' interest in learning, enhances understanding and memory of the theory, the students develop observation ability and ability to explain the actual random phenomena with the theory. Such as the two distributions of Poisson approximation and the normal approximation, density function distributed graphics and graphics with the variation of parameters, can be displayed visually, this point is the 
traditional teaching difficulty. The second class is the experimental operation statistics, which is a kind of experimental method to statistical sample inspection. We created a sample corresponding experimental teaching in confidence interval estimation and testing in teaching, so as to improve the students' interest and desire of active learning. The third class for the computer simulation experiment that is complex and random phenomenon according to the probability model, through the computer simulation of "direct" description of the experimental method. Such as Monte Carlo method, the general random variable, random events, random process on the computer simulation described as uniformly distributed random variable, through programming in the computer.

In the teaching of probability theory, teachers should be possible to "return" to the actual background, set up suitable problem scene, provide rich visual background materials observation experiment, operation, conjecture, induction, validation and so on, that to guide the students to participate in teaching activities, which will assist in the training of students' practical ability in the teaching of mathematical concepts and methods,. Combined with the background of market economy, strengthening the application practice of probability and statistics, which is the effective way to improve students' statistical probability of interest, is the effective way to make up for lack of knowledge of probability and statistics theory teaching. On the one hand, we use the probability statistics class discussion, analyzing of some classical examples in data modeling, using thought method to strengthen the data modeling, data modeling steps. On the other hand, we launch the students to participate in social practice, in-depth study of the actual, investigation, collection of experimental data of material, and encourage them to solve the general problem by establishing the model of probability statistics for the corresponding.

\section{CONCLUSIONS}

The teaching reform of Probability theory and mathematical statistics is a long-term work, we just made the exploration from some aspects, but it still need to keep learning and improving for the teaching reform of the course and teaching level.

\section{ACKNOWLEDGMENT}

Hebei province of China scientific research subject in "Twelfth Five Year Plan" (13090074)

Handan city of China education scientific research project (1114003)

\section{REFERENCES}

[1] Influence of the development in Wuhan city on lake resource[A]. Environmental Science and Information Application Technology Volume 1[C]. 2009.

[2] Synthesis of Water Allocation Network in Process Industries[A]. Environmental Science and Information Application Technology Volume 2[C]. 2009

[3] J. Sheng,S. Q. Xie,C. Y. Pan.Probability Theory and Mathematical Statistics (in Chinese). . 2008.

[4] Huang baoxing."Application of Matlab in the teaching of probability theory and mathematical statistics". Science and Technology Information . 2008.

[5] Discussion of Educational Reform on Program Design Course[A]. Proceedings of the 2011 International Conference on Education Science and Management Engineering(part 2)[C]. 2011.

[6] Discussion on methods of initial water rights allocation in freshwater lake basin[A]. Proceedings of 2010 The 3rd International Conference on Power Electronics and Intelligent Transportation System(Volume 4)[C]. 2010.

[7] Lisowski J.A differential game model of ship control process. Proc. of the IFAC 7th Triennial World Congress . 1978.

[8] Lisowski J.Game control of moving objects. Proc. of the 15th IFAC World Congress . 2002.

[9] Rubinovich E Ya.Elementary differential game of alternatepursuit wih miss type criterion. Proc. of the 8th International Symposium on Dynamic Games and Applications . 1998 